\title{
The Role of Calcium in the Desensitization of Capsaicin Responses in Rat Dorsal Root Ganglion Neurons
}

\author{
Patricia A. Koplas, Robert L. Rosenberg, and Gerry S. Oxford \\ Curriculum in Neurobiology and the Departments of Physiology and Pharmacology, University of North Carolina at Chapel \\ Hill, Chapel Hill, North Carolina 27599
}

\begin{abstract}
Capsaicin (Cap) is a pungent extract of the Capsicum pepper family, which activates nociceptive primary sensory neurons. Inward current and membrane potential responses of cultured neonatal rat dorsal root ganglion neurons to capsaicin were examined using whole-cell and perforated patch recording methods. The responses exhibited strong desensitization operationally classified as acute (diminished response during constant Cap exposure) and tachyphylaxis (diminished response to successive applications of Cap). Both acute desensitization and tachyphylaxis were greatly diminished by reductions in external $\mathrm{Ca}^{2+}$ concentration. Furthermore, chelation of intracellular $\mathrm{Ca}^{2+}$ by addition of either EGTA or bis(2-aminophenoxy)ethane- $N, N, N^{\prime}, N^{\prime}$-tetraacetic acid to the patch pipette attenuated both forms of desensitization even in normal $\mathrm{Ca}^{2+}$. Release of intracellular $\mathrm{Ca}^{2+}$ by caffeine triggered acute desensitization in the absence of extracellular $\mathrm{Ca}^{2+}$, and barium was found to effectively substitute for calcium in supporting desensitization.
\end{abstract}

Cap activated inward current at an $\mathrm{ED}_{50}$ of $728 \mathrm{~nm}$, exhibiting cooperativity (Hill coefficient, 2.2); however, both forms of desensitization were only weakly dependent on [Cap], suggesting a dissociation between activation of Cap-sensitive channels and desensitization. Removal of ATP and GTP from the intracellular solutions resulted in nearly complete tachyphylaxis even with intracellular $\mathrm{Ca}^{2+}$ buffered to low levels, whereas changes in nucleotide levels did not significantly alter the acute form of desensitization. These data suggest a key role for intracellular $\mathrm{Ca}^{2+}$ in desensitization of Cap responses, perhaps through $\mathrm{Ca}^{2+}$-dependent dephosphorylation at a locus that normally sustains Cap responsiveness via ATP-dependent phosphorylation. It also seems that the signaling mechanisms underlying the two forms of desensitization are not identical in detail.

Key words: capsaicin; sensory neurons; patch clamp; desensitization; calcium; nociceptors; dorsal root ganglion
The ability of neurons to adapt to specific stimuli is crucial for the normal physiological operation of the nervous system. Through the process of desensitization, a neuron can diminish its overall response to a particular chemical, physical, or electrical signal. For example, the inactivation of glutamate-dependent ion channels within the CNS seems to play a protective role during a prolonged exposure to glutamate by limiting potentially cytotoxic calcium overload in the neurons (Choi, 1988). Since the early characterization of the desensitization of acetylcholine responses at the frog neuromuscular junction by Katz and Thesleff (1957), receptors in a wide range of excitable tissues have demonstrated desensitization and provided model systems to investigate the possible mechanisms underlying this change in sensitivity to agonists.

The desensitization of sensory neurons is particularly important considering their crucial role in the physiological perception of and reaction to the external environment. Capsaicin (8-methyl- $N$-vanillyl6-nonenamide) is the active ingredient in hot peppers that selectively targets polymodal nociceptive and warmth-sensitive thermoreceptor

\footnotetext{
Received Sept. 26, 1997; revised Feb. 27, 1997; accepted March 6, 1997.

This work was submitted in partial fulfillment of the requirements for the Ph.D. in neurobiology at the University of North Carolina at Chapel Hill (P.A.K.) and was supported by National Institutes of Health Grants NS18788 (G.S.O.) and HL49449 (R.L.R.). We thank William Maixner and Sid Simon for helpful discussions through the course of this work. Expert technical assistance was provided by Rakhshi Khan. Correspondence should be addressed to Gerry S. Oxford, Department of Physiology, University of North Carolina School of Medicine, Campus Box 7545, 04 Medical Science Research Building, Chapel Hill, NC 27599.

Copyright (C) 1997 Society for Neuroscience $0270-6474 / 97 / 173525-13 \$ 05.00 / 0$
}

fibers of the C and A $\delta$ classes (Jancso et al., 1967; Bevan and Solcsanyi, 1990; Dray, 1992; Dray and Dickenson, 1993). Capsaicin excites afferent neurons through the activation of a nonselective cation channel, leading to depolarization and release of neurotransmitters, including substance $\mathrm{P}$, from sensory nerve terminals (Bevan and Forbes, 1988; Holzer, 1988). The capsaicin response exhibits a pronounced desensitization that functionally inactivates nociceptive neurons subsequent to the initial excitation (Jancso et al., 1967). This selective inactivation of nociceptive neurons by capsaicin has generated extensive research on the possible therapeutic effectiveness of capsaicin as a clinical analgesic tool (Bernstein, 1987; Maggi, 1991; Wallengren, 1991; Breneman et al., 1992; Campbell et al., 1993; Epstein and Marcoe, 1994).

In the present study we investigate the mechanisms of desensitization of the capsaicin-activated current. Desensitization exhibited by capsaicin can be divided into two phenomenological categories: (1) "acute desensitization," an inactivation of the current during a prolonged application of capsaicin; and (2) "tachyphylaxis," a diminution of the maximal current amplitude during successive deliveries of the same capsaicin concentration. It has been observed previously that tachyphylaxis of capsaicin-activated currents is affected by changes in extracellular calcium (Santicioli et al., 1987; Yeats et al., 1992; Cholewinski et al., 1993), but there are no comparable observations concerning the acute desensitization of capsaicin responses. Although examination of the published data suggests that acute desensitization occurs during extended applications of capsaicin in calcium-containing external solutions (Marsh et al., 1987; Petersen and LaMotte, 1991; Bevan 
et al., 1992), this phase of desensitization has not been evaluated in detail.

The experiments described in this paper were designed to characterize the acute desensitization and tachyphylaxis of the capsaicin-activated channel in cultured neonatal rat dorsal root ganglion (DRG) neurons and to evaluate the role of divalent cations in these processes. In addition to confirming the earlier reports of extracellular calcium dependence, we demonstrate that the locus of this sensitivity is a rise in intracellular $\mathrm{Ca}^{2+}$. Furthermore, we show that desensitization can be supported by other divalent cations, including $\mathrm{Ba}^{2+}$.

\section{MATERIALS AND METHODS}

Dissociations and cultures of dorsal root ganglion neurons. Sprague Dawley rat pups between the ages of 2 and $8 \mathrm{~d}$ were used for preparation of the DRG cultures. After the DRGs were collected into a Petri dish containing Ca- and Mg-free HBSS (CMFH), a scalpel was used to trim the remaining nerve roots and connective tissue from the ganglia. All cleaned ganglia were collected into a sterile $15 \mathrm{ml}$ polystyrene centrifuge tube containing approximately $2 \mathrm{ml}$ of $\mathrm{CMFH}$ with $0.01 \%$ added trypsin (Sigma, St. Louis, MO) (type III, bovine pancreas) and incubated at $37^{\circ} \mathrm{C}$ for $6-10 \mathrm{~min}$ in $5 \% \mathrm{CO}_{2}$.

After the trypsin incubation, the DRGs were rinsed twice with a Ham's F-12 growth medium (Life Technologies, Gaithersburg, MD) supplemented with $10 \%$ fetal bovine serum and $100 \mathrm{U} / \mathrm{ml}$ penicillin-streptomycin. After the rinses, the DRGs were resuspended in 1-2 ml of growth medium and triturated with a fire-polished siliconized glass pipette. The dissociated neurons were plated in 12-well dishes containing plastic coverslips previously exposed to ultraviolet radiation for $15 \mathrm{~min}$ and coated with $0.04 \mathrm{mg} / \mathrm{ml}$ sterile poly-D-lysine. After the neurons were returned to the incubator for $30-60 \mathrm{~min}$ to allow proper adherence to the coverslips, $1 \mathrm{ml}$ of growth medium containing $50 \mathrm{ng} / \mathrm{ml}$ nerve growth factor (Sigma) (nerve growth factor $2.5 \mathrm{~S}$, mouse submaxillary gland) was added to each well. The final density of the plated cells was relatively high, because cell density seemed to affect both the success rate of patch-clamp recordings and the amplitude of capsaicin responses. The experiments were conducted exclusively on cells cultured for only 20-30 hr to help reduce both cell culture artifacts and the heterogeneity of the capsaicin responses.

Electrophysiological solutions. All experimental solutions were adjusted to $\mathrm{pH} 7.4$ and osmolarity of $\sim 300 \mathrm{mOsm}$. The standard external solution (SES) contained (in mM): $145 \mathrm{NaCl}, 5 \mathrm{KCl}, 2 \mathrm{CaCl}_{2}, 1 \mathrm{MgCl}_{2}, 10 \mathrm{HEPES}$, and 10 glucose. The calcium-free external solution ( 0 Ca-ES) contained no added calcium and $1 \mathrm{~mm}$ EGTA to chelate ambient calcium. The standard internal solution (SIS) consisted of (in $\mathrm{mM}$ ): 130 potassium aspartate, $20 \mathrm{KCl}, 10 \mathrm{HEPES}, 10$ glucose, and $0.10 \mathrm{GTP}$; in addition, SIS contained a nucleotide-regenerating system consisting of (in $\mathrm{mM}$ ): 2 cAMP, $2 \mathrm{MgATP}$, and $5 \mathrm{Na}_{2}$ creatine phosphate, and $20 \mathrm{U} / \mathrm{ml}$ creatine phosphokinase (Forscher and Oxford, 1985). In a subset of experiments, EGTA or bis(2-aminophenoxy)ethane- $N, N, N^{\prime}, N^{\prime}$-tetra-acetic acid (BAPTA) was included in the internal solution (EGTA-IS or BAPTA-IS, respectively) at a concentration of $10 \mathrm{mM}$.

For all of the experiments, drug solutions were delivered to the cells via a $U$ tube perfusion system with a delivery response time on the order of milliseconds (Oxford and Wagoner, 1989). To confirm the proper delivery of all solutions throughout the course of an experiment, each solution contained fast green dye to monitor the drug delivery visually. In all control experiments, drug-free external solutions containing the dye had no effects on membrane current. The $10 \mu \mathrm{M}$ capsaicin (LC Laboratories) stock was prepared in ethanol, and vacuum-dried aliquots were stored at $-70^{\circ} \mathrm{C}$. Caffeine was obtained from Sigma.

Electrophysiological techniques Standard whole-cell patch-clamp methods were used to record the membrane current and voltage from individual DRG neurons. The whole-cell responses activated by capsaicin were recorded with an Axopatch 1B amplifier (Axon Instruments) and filtered at $5 \mathrm{kHz}$ with a low-pass four-pole Bessel filter. N51A glass tubing (Drummond Scientific, Broomall, PA) was used to make the recording electrodes by a two-step process on a Narashige PP-83 electrode puller. After pulling, electrodes were dipped in melted dental wax (Kerr sticky wax) to minimize the capacitive properties. Immediately before experiments, electrodes were fire polished with a custom-built microforge to a final electrode resistance of 3-6 M 2 . All experiments were performed at room temperature $\left(21-23^{\circ} \mathrm{C}\right)$. After seal formation and establishment of the whole-cell recording mode, cells were dialyzed for $5 \mathrm{~min}$ before drug application. An inward current response to capsaicin of $>10 \mathrm{pA}$ was considered a positive response. The holding potential in all voltage-clamp experiments was $-60 \mathrm{mV}$. In all recordings, whole-cell capacitance compensation was used, and $80 \%$ of the series resistance was compensated electronically for the voltage-clamp experiments. The access resistance values typically ranged from 3 to $15 \mathrm{M} \Omega$. All recordings were made from cells displaying no neurite processes to reduce errors associated with poor spatial control of membrane potential.

The data were collected on videotape using a digital audio processor interface and redigitized off-line by computer for analysis with Axotape software (Axon Instruments). The results were analyzed using the Student's $t$ test, one-way and two-way ANOVA statistical tests, and multivariant ANOVA using the Tukey-Kramer correction for sample size (Systat, Evanston, IL).

Perforated patch technique We used the perforated patch technique to allow electrophysiological recordings of neurons in which the intracellular environment had been minimally disrupted (Horn and Marty, 1988). For our perforated patch recordings, amphotericin $\mathrm{B}$ was used at a final concentration of $200 \mu \mathrm{g} / \mathrm{ml}$, and the internal solution was a $\mathrm{K}_{2} \mathrm{SO}_{4}$-based solution.

Intracellular calcium imaging All calcium imaging experiments were performed on intact DRG neurons plated on glass coverslips with a polylysine/laminin substrate. This substrate procedure was used because the neurons failed to adhere properly to the glass if only poly-D-lysine was present. These neurons exhibited extensive processes and interneuronal connections within the first $24 \mathrm{hr}$ after plating in contrast to the round cell morphology observed in the absence of laminin.

The fluorescent indicator used in the imaging experiments was fluo-3 (Molecular Probes, Eugene, OR). The dye was prepared as a $5 \mathrm{~mm}$ stock in dimethylsulfoxide/Pluronic F127 and stored at $-20^{\circ} \mathrm{C}$. The stock was diluted in SES for a final concentration of $5 \mu \mathrm{M}$. The cells were rinsed three times with PBS and incubated in fluo-3 AM for $30-60$ min $37^{\circ} \mathrm{C}$. After the incubation, the slips were rinsed once with SES and placed in a glass bottom recording chamber on the stage of an inverted microscope (Nikon Diaphot). All control and drug-containing solutions were delivered to the cells by a continuous flow bath exchange system.

Light from a 75-W xenon arc lamp was passed through an infrared water filter and a Uniblitz shutter and focused onto a liquid light guide (Oriel Corp.), which both "scrambles" and transmits light to a custom filter cube (Omega Optical). For fluo-3, the excitation wavelength was at $485 \mathrm{~nm}$, and the fluorescence emission was bandpass filtered at $535 \mathrm{~nm}$. Epifluorescence emission was collected via a quartz phase objective (40 or $100 \times)$. On the emission side, light was amplified by a VideoScope KS-1381 intensifier and passed to a Dage 72 CCD camera. Video images were captured on an 80386-based microcomputer using the Image-1 software package (Universal Imaging Corporation, West Chester, PA), which permits logging of fluorescence intensity versus time for several cells (indicated by "regions of interest" boundaries) as a measure of intracellular $\left[\mathrm{Ca}^{2+}\right]$ changes (arbitrary units).

\section{RESULTS}

\section{Desensitization of capsaicin responses}

We first characterized and verified the capsaicin responses in our DRG neuron cultures because culture conditions and plating substrate can have a substantial impact on cellular phenotype. A typical current activated by $1 \mu \mathrm{M}$ capsaicin is shown in Figure 1. Capsaicin activated an inward current carried predominately by sodium ions in the bath solution with a small additional contribution from external calcium ions (data not shown). In neurons voltage clamped at a holding potential of $-60 \mathrm{mV}, 1 \mu \mathrm{M}$ capsaicin activated inward currents that ranged in peak amplitude from 50 $\mathrm{pA}$ to $>19 \mathrm{nA}$ (producing saturation of the patch-clamp amplifier). The mean current amplitude for a representative set of neurons was $2.17 \pm 0.33 \mathrm{nA}(n=30)$.

As seen in Figure 1 (inset), there was a delay between the initial exposure to capsaicin and activation of the inward current. In all experiments, the duration of this activation interval was quite variable and ranged from 1 to $5 \mathrm{sec}$. The delay was not the result of a time required for the drug to reach the cell, because the $U$ tube perfusion system has a delivery response time on the order of 


\section{$1 \mu \mathrm{M}$ Capsaicin}

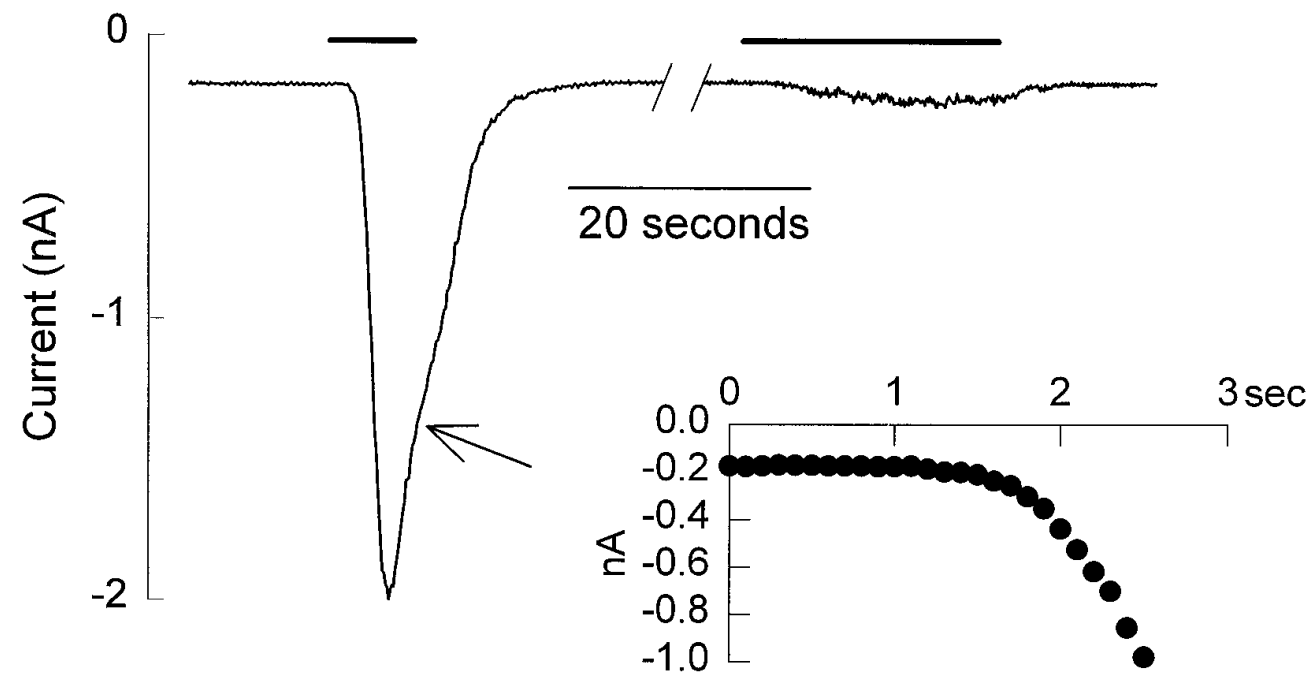

Figure 1. Capsaicin-activated current responses in a rat DRG neuron. One micromolar capsaicin was delivered twice (horizontal bars) to a single neuron voltage clamped at $-60 \mathrm{mV}$ with an interdose interval of $2 \mathrm{~min}$, indicated by the break in the trace. External and internal solutions were SES and SIS, respectively. Note that acute desensitization begins before capsaicin is removed in the first application but is not allowed to proceed beyond approximately $25 \%$ (arrow). The initial response of the neuron to capsaicin is shown on an expanded time scale in the inset, demonstrating the delay between capsaicin application and current response.

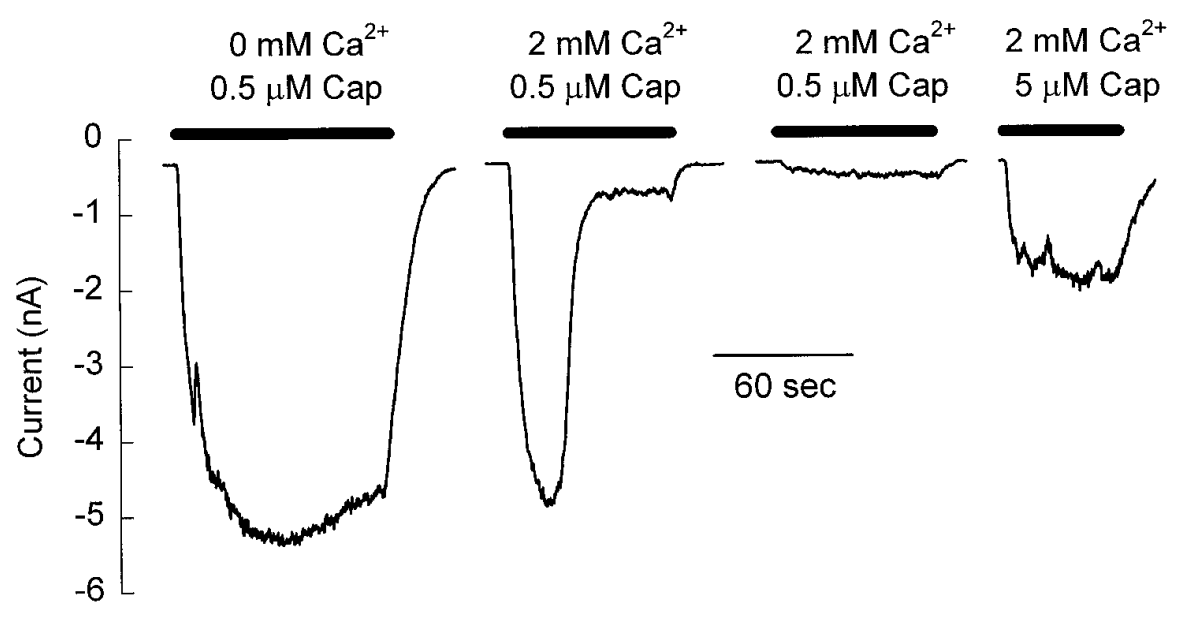

Figure 2. Desensitization of capsaicin responses depends on extracellular calcium. Membrane currents at $-60 \mathrm{mV}$ were recorded as $0.5 \mu \mathrm{M}$ capsaicin was delivered three successive times to a single DRG neuron followed by an application of $5 \mu \mathrm{M}$ capsaicin (horizontal bars) with 2 min intervals between applications. The first application was performed in $0 \mathrm{Ca}-\mathrm{ES}$, and subsequent applications were performed in SES. The internal pipette solution was BAPTA-IS in all cases. Note the striking desensitization that occurs when calcium is reintroduced to the bath for the second application.
20-30 msec (Oxford and Wagoner, 1989). Rather, the slow activation of the capsaicin-dependent channels suggests that a coupling mechanism involving other membrane-associated proteins or cellular messengers is the rate-limiting step in the current activation. Alternatively, a slow diffusion of capsaicin through the plasma membrane to an intramembrane or intracellular site of action may be responsible for the delay in activation.

The capsaicin-activated current exhibits two types of desensitization, both of which are illustrated in Figure 1. We have defined acute desensitization as the decrease in inward capsaicin-activated current during an extended application of capsaicin. We specifically distinguish this from tachyphylaxis, which refers to the diminution of the current amplitude observed during repeated applications of the same capsaicin concentration. Overall, the acute desensitization and tachyphylaxis of capsaicin responses throughout this study were quite heterogeneous in that some currents displayed complete desensitization, whereas other capsaicin responses only partially desensitized. One explanation for this variability is that the mechanisms underlying acute desensitization and tachyphylaxis result in the inactivation of a fraction or subpopulation of the channels. The additional variability in activation kinetics of capsaicin-dependent currents may also reflect the con- tribution of subtypes of capsaicin-gated channels. The existence of capsaicin receptor channel subtypes has previously been suggested by Liu and Simon (1994) based on the rapid and slow inward currents activated by capsaicin in rat trigeminal neurons.

\section{Calcium dependence of desensitization}

We next sought to determine whether external calcium was necessary for and therefore integral to capsaicin-induced acute desensitization and tachyphylaxis in our culture preparation of DRG neurons. Figure 2 illustrates consecutive capsaicin responses recorded in the absence and presence of extracellular calcium. In the $0 \mathrm{Ca}-\mathrm{ES}$ solution, negligible desensitization was observed during the first capsaicin challenge. After switching to the SES containing $2 \mathrm{~mm}$ external calcium, the capsaicin-activated current desensitized to only $15 \%$ of the maximal current amplitude. The peak current magnitude decreased very little between the first two applications, indicating a lack of tachyphylaxis in the absence of $\mathrm{Ca}^{2+}$. In contrast, a pronounced tachyphylaxis was evident in the third response, presumably because of the presence of extracellular calcium during the second activation of the capsaicindependent current. The channels were not completely inactivated, 

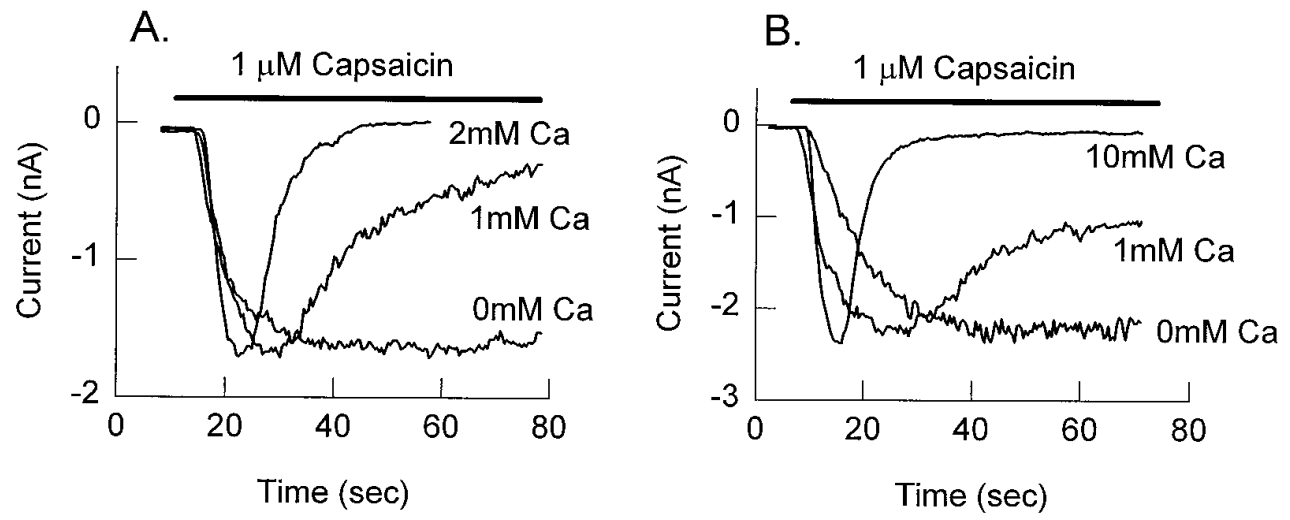

Figure 3. Calcium dependence of acute desensitization. $A$, Current responses of three separate neurons to a $60 \mathrm{sec}$ application of $1 \mu \mathrm{M}$ capsaicin at the indicated extracellular calcium concentrations $(0,1$, and $2 \mathrm{~mm})$. In each case the intracellular solution was SIS. Current amplitudes were normalized to that of the largest response to compare desensitization kinetics. $B$, Current responses of another three cells to capsaicin at the indicated extracellular calcium concentrations $(0,1$, and $10 \mathrm{mM})$. These cells were dialyzed with BAPTAIS. $C$, Summary graph of the percentage of acute desensitization (mean \pm SEM) observed during a $60 \mathrm{sec}$ application of $1 \mathrm{~mm}$ capsaicin at various external calcium concentrations and the indicated intracellular solutions (open bars, SIS; filled bars, EGTA-IS; striped bars, BAPTA-IS). The number of neurons in each trial is indicated over each bar.

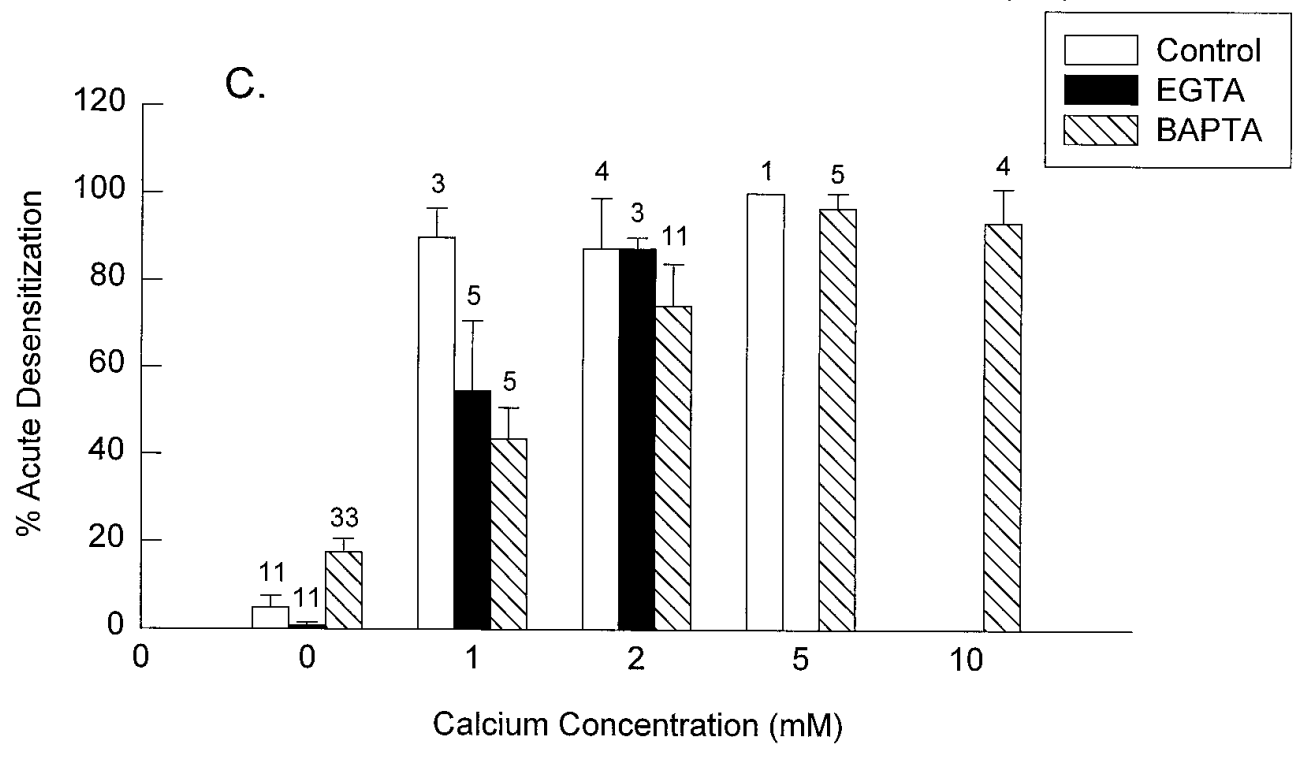

in that a subsequent challenge with a higher concentration of capsaicin $(5 \mu \mathrm{M})$ stimulated a substantial inward current.

\section{Concentration dependence of calcium-facilitated desensitization}

In an effort to quantify the relationship between external calcium and desensitization, the external calcium concentration was varied within the range of $0-10 \mathrm{~mm}$, and both the acute desensitization and tachyphylaxis of capsaicin responses were assessed. We also manipulated the relative concentration of free internal $\mathrm{Ca}^{2+}$ by including $\mathrm{Ca}^{2+}$ chelators in the pipette solution. BAPTA and EGTA were both tested, because these compounds differ in their efficiency of calcium chelation. Although each chelator is highly selective for $\mathrm{Ca}^{2+}$ over $\mathrm{Mg}^{2+}$, BAPTA mediates a faster $\mathrm{Ca}^{2+}$ chelation with no $\mathrm{pH}$ sensitivity, because protons are not released during the binding of $\mathrm{Ca}^{2+}$ (Tsien, 1980). The three internal solutions tested were: (1) control, with no added chelator (SIS); (2) $10 \mathrm{~mm}$ BAPTA (BAPTA-IS); and (3) $10 \mathrm{~mm}$ EGTA (EGTA-IS).

The experimental protocol performed to test acute desensitization used a $60 \mathrm{sec}$ challenge with $1 \mu \mathrm{M}$ capsaicin. For the tachyphylaxis protocol, a series of successive 15-20 sec applications of $1 \mu \mathrm{M}$ capsaicin with interdose intervals of 2 min was delivered. Experiments testing the effect of the interdose interval on tachyphylaxis indicated that there was no significant difference in the extent of tachyphylaxis observed for interval durations ranging from $30 \mathrm{sec}$ to $20 \mathrm{~min}$ (results not shown). This finding agrees with the results of Cholewinski et al. (1993), who observed only limited recovery of capsaicin-stimulated increases in intracellular $\mathrm{Ca}^{2+}$ at $25 \mathrm{~min}$.

\section{Acute desensitization}

Overall, the results indicated that both the rate and degree of acute desensitization were dependent on the concentration of external calcium. Representative traces recorded in various external $\mathrm{Ca}^{2+}$ concentrations with either SIS or BAPTA-IS are shown in Figure 3, $A$ and $B$, respectively. It is evident that the capsaicin responses displayed little acute desensitization in the absence of external calcium. As the external calcium was increased, the rate and degree of acute desensitization was enhanced. The presence of internal chelation capacity seemed to reduce the acute desensitization at lower $\mathrm{Ca}$ concentrations. This can be seen from a comparison of the acute desensitization observed for the $1 \mathrm{mM}$ $\mathrm{Ca}^{2+}$ concentration in SIS (Fig. $3 A$ ) and BAPTA-IS (Fig. 3B).

The summary of the calcium dependence of the degree of acute desensitization is presented in Figure $3 C$. For 0 Ca-ES and all three internal solutions, the acute desensitization of the capsaicin responses was absent or minimal in the 55 cells tested. As the external calcium concentration was raised, a larger percentage of cells demonstrated acute desensitization, and the degree of desensitization also increased. Furthermore, at the low $\mathrm{Ca}^{2+}$ concentration of $1 \mathrm{~mm}$, desensitization was inhibited by internal $\mathrm{Ca}^{2+}$ buffering by either EGTA or BAPTA.

Statistical analysis of the results for the 0,1 , and $2 \mathrm{~mm}$ external $\mathrm{Ca}^{2+}$ solutions indicated a significant effect of external calcium concentration $(p<0.0005)$, internal solution $(p=0.055)$, and a 

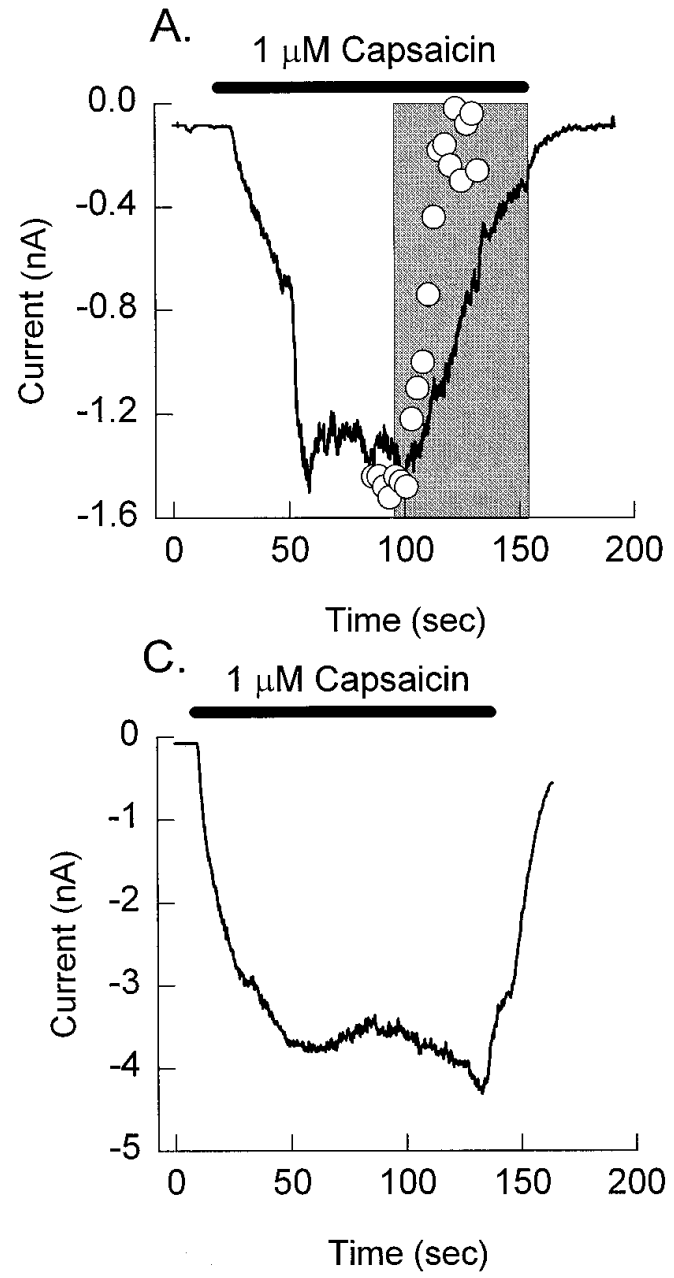
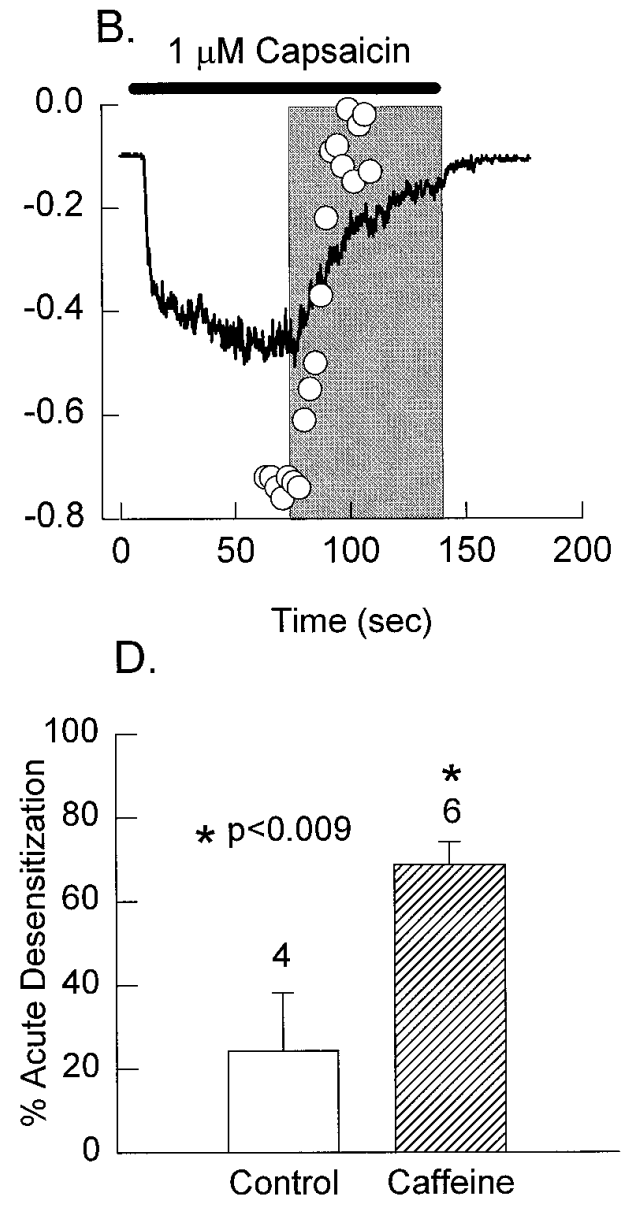

Figure 4. Acute desensitization is triggered by elevations of intracellular calcium. Current responses to a 2 min application of $1 \mu \mathrm{M}$ capsaicin were recorded in three separate DRG neurons in the absence of extracellular calcium (0 Ca-ES). After 1 min of the capsaicin application (horizontal lines), $10 \mathrm{~mm}$ caffeine was added $(A$ and $B$, shaded bars) in the continued presence of capsaicin to trigger the release of calcium from intracellular stores. Note the rapid decline in current after caffeine application. In another experiment, the change in intracellular calcium was monitored in three different neurons by fluo-3 fluorescence. The normalized and averaged responses are depicted by the open circles in $A$ and $B$ to demonstrate that the time course of calcium elevation is consistent with the suppression in capsaicin-induced current. In $C$, the capsaicin-induced current could be maintained in the absence of caffeine during the entire 2 min capsaicin application. A comparison of acute capsaicin desensitization between control and caffeine-treated neurons $(D$, mean $\pm \mathrm{SEM})$ indicates a significant potentiation by caffeine $(p<$ 0.009 , Student's $t$ test). significant interaction between these two variables $(p=0.010$, two-way ANOVA). Results of the posthoc analysis indicated that the inclusion of BAPTA ( $p=0.014)$ significantly reduced the degree of desensitization for the $1 \mathrm{~mm}$ external $\mathrm{Ca}^{2+}$ condition relative to control, whereas the addition of EGTA had an effect of only marginal significance $(p=0.105)$. There was no significant difference for the three internal solutions in the $0 \mathrm{~mm}(p>0.455)$ and $2 \mathrm{~mm}(p>0.2) \mathrm{Ca}^{2+}$ solutions.

The dependence of acute desensitization on calcium concentration raises the question of whether the site for calcium modulation of acute desensitization is extracellular or intracellular. The sensitivity of acute desensitization to internal chelation suggests that intracellular calcium concentration is the important variable for activation of acute desensitization processes. To further explore the possibility that intracellular calcium is the key effector in acute desensitization, we investigated the action of caffeine on capsaicin responses in the absence of extracellular calcium. Rat DRG and other neurons have been shown to release calcium from internal stores in response to a caffeine challenge (Holliday et al., 1991; Benham et al., 1992; Schmigol et al., 1994). The presence of caffeine-sensitive calcium stores in our cultures of DRG neurons was confirmed in calcium-imaging experiments using fluo-3 as an indicator. As previously demonstrated in $0 \mathrm{Ca}-\mathrm{ES}$, the capsaicinactivated current typically reaches a plateau amplitude and exhibits little to no acute desensitization (see Figs. 2 and 3). The ability of intracellular calcium to trigger acute desensitization in the absence of external calcium influx was tested by an application of
$10 \mathrm{~mm}$ caffeine to release calcium from internal stores during a capsaicin response in $0 \mathrm{Ca}-\mathrm{ES}$.

A challenge with $10 \mathrm{~mm}$ caffeine induced acute desensitization of the capsaicin-activated currents in the absence of extracellular calcium (Fig. 4). As seen by example for two different neurons in Figure $4, A$ and $B$, the current amplitude was relatively stable during the first minutes of the capsaicin delivery, whereas the current rapidly diminished after approximately $10 \mathrm{sec}$ of exposure to caffeine. The normalized average time course of elevation in intracellular calcium measured by fluo-3 brightness on separate neurons $(n=3)$ is illustrated by the open circles (Fig. 4A,B). An example of a control cell in which the capsaicin-stimulated current exhibited a large activation and no acute desensitization is shown in Figure $4 C$. The summary of results for all caffeine experiments is presented in Figure $4 D$, indicating that the level of acute desensitization measured in the caffeine-treated cells was significantly larger in comparison with the control condition $(p<0.009$, Student's $t$ test). These findings indicate that intracellular calcium indeed increases in our DRG neurons in response to caffeine with sufficient rapidity to precede changes in current and furthermore suggests that this rise in internal calcium is capable of supporting acute desensitization processes in the absence of external calcium and calcium influx.

\section{Tachyphylaxis}

In general, the degree of tachyphylaxis increased with increases in external calcium concentration as seen for acute desensitization. 


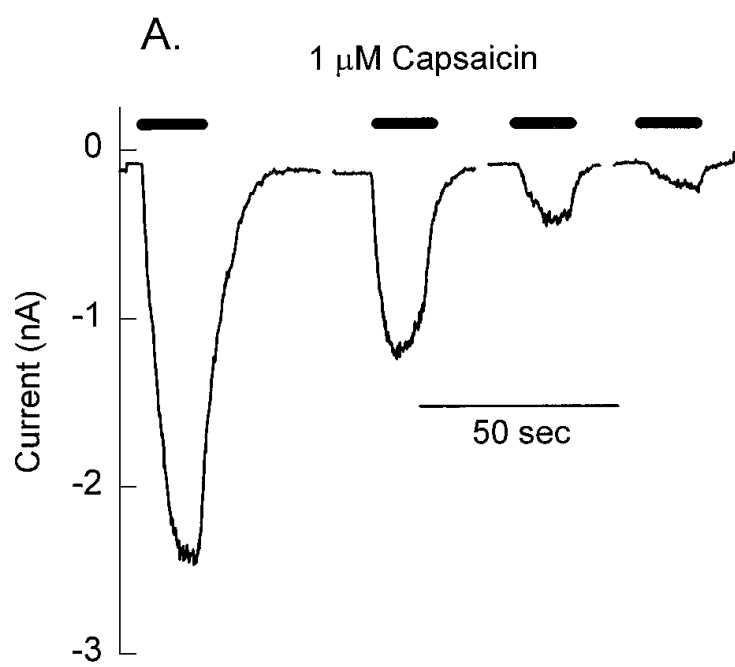

C.

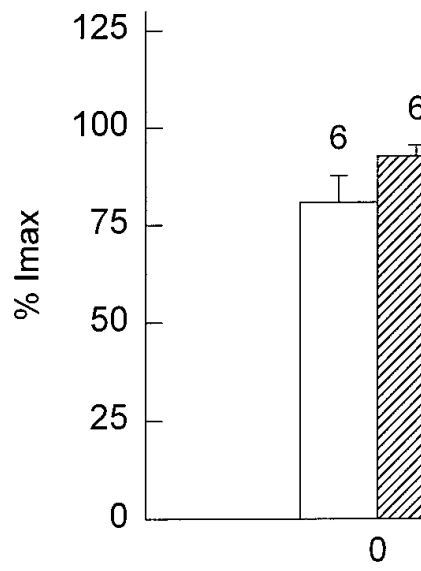

1
B.

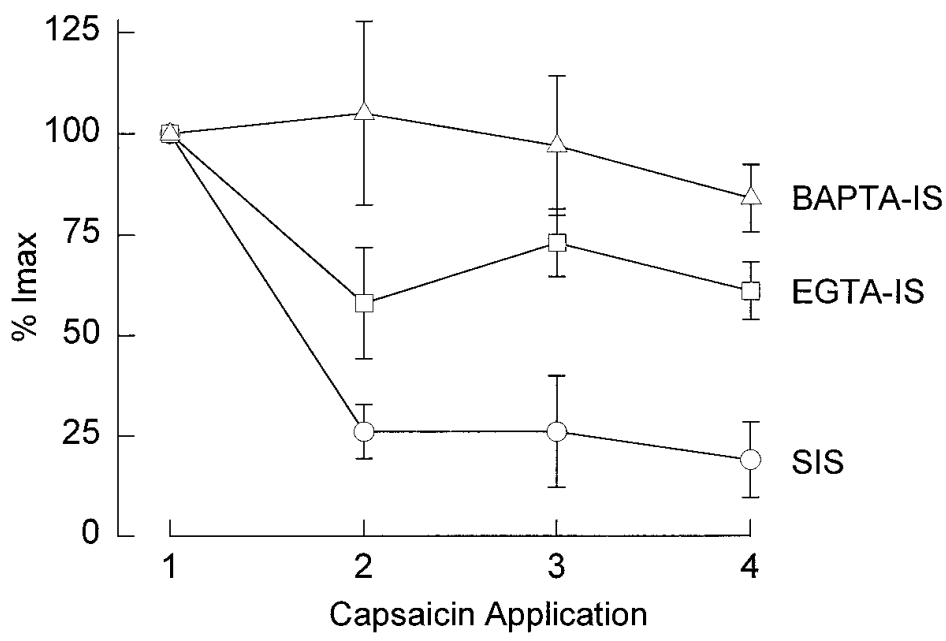

7

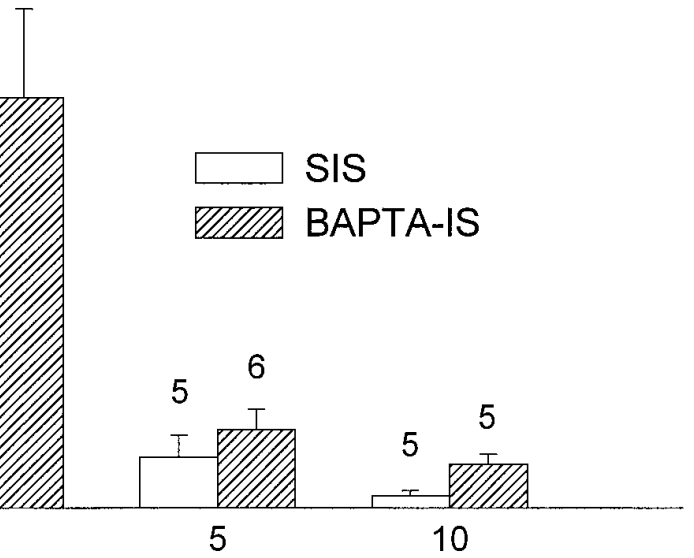

2

5

10

Calcium Concentration (mM)

Figure 5. Calcium dependence of capsaicin tachyphylaxis. A, An example of tachyphylaxis to four consecutive applications of $1 \mu \mathrm{M}$ capsaicin (horizontal bars) given at 2 min intervals (breaks in the trace). The external and internal solutions were SES and SIS, respectively. $B$, A plot of the normalized mean ( \pm SEM) peak capsaicin-activated current as a function of the number of sequential applications. In all cases the external solution was SES, whereas the intracellular (pipette) solution was as indicated. Note how chelation of intracellular calcium retards the tachyphylaxis. $C$, Mean ( \pm SEM) capsaicinactivated current during the second of four consecutive applications $(1 \mu \mathrm{M})$ normalized to the maximum response to the first application for each neuron. Data are presented for intracellular dialysis with SIS (open bars) and BAPTA-IS (striped bars) for the number of neurons indicated above each bar.

An example of the tachyphylaxis behavior recorded under control conditions (SIS internal) in an external $\mathrm{Ca}^{2+}$ concentration of 2 $\mathrm{mm}$ is shown in Figure $5 A$. It is evident that the tachyphylaxis proceeds with successive capsaicin applications. A summary of the tachyphylaxis for all three internal solutions is shown in Figure $5 B$. The initial maximal current amplitude $\left(I_{\max }\right)$ corresponds to the maximal current amplitude observed during the initial delivery of $1 \mu \mathrm{M}$ capsaicin. The results are presented as the percentage of this initial capsaicin-activated current calculated for each response elicited by four consecutive capsaicin applications. It should be noted that in contrast to the reduced currents typically observed during successive applications of capsaicin, an increase in the peak current amplitude was observed for three of seven cells during dialysis with BAPTA-IS. This increase in current amplitude is similar to the potentiation phenomenon reported by Yeats et al. (1992), who observed an increase in capsaicin responses in the presence of external barium and internal EGTA chelation. In our experiments, the potentiation was occasionally observed under a variety of solution conditions but was most pronounced in solutions containing external barium and internal BAPTA (see Fig. $7 B$ below). At present, the mechanism underlying this increase in current is not known.

The mean tachyphylaxis observed for the second capsaicin application across the entire range of external Ca concentration is compared between SIS and BAPTA internals solutions in Figure $5 C$. It is evident that the actual calcium concentration at which the tachyphylaxis of the second capsaicin response reached $50-75 \%$ changed markedly with calcium chelation. Statistical analysis of these data revealed a significant effect of the internal solution $(p=0.001)$, the external calcium concentration $(p<0.0005)$, and an interaction between these two independent variables $(p=$ 0.066, two-way ANOVA). A further comparison of specific pairs of solution conditions indicated the following: (1) at $0 \mathrm{~mm}$ external $\mathrm{Ca}^{2+}$, there was no significant difference in the tachyphylaxis 


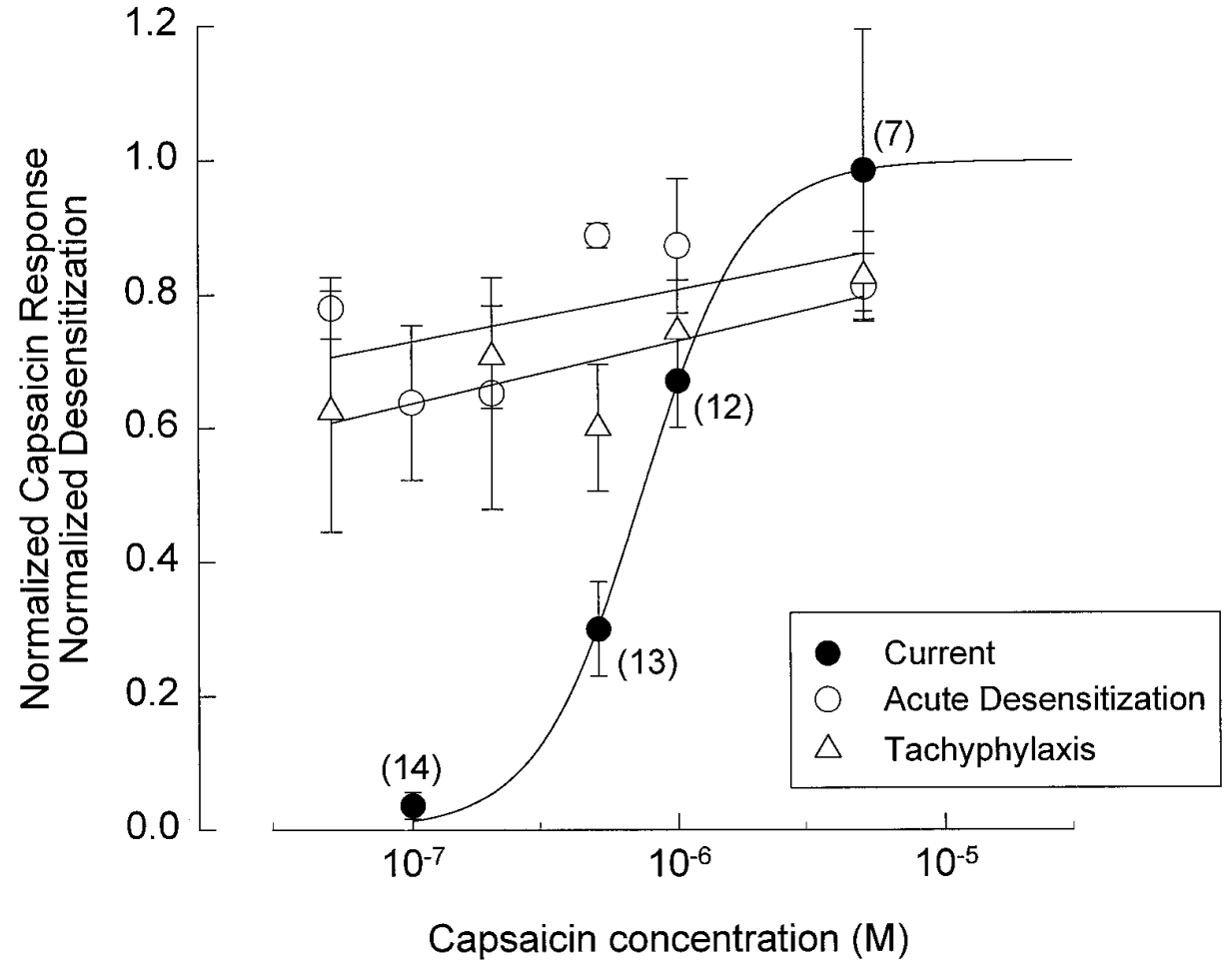

Figure 6. Desensitization is not tightly coupled to current activation. Capsaicin doseresponse curves are represented as mean \pm SEM values of normalized maximum current during a single agonist application ( filled circles), fractional current decay during agonist (acute desensitization, open circles), or fractional loss of current during the second of two consecutive agonist applications (tachyphylaxis, open triangles). Straight lines through the desensitization responses are simple linear regressions. The curve is a fit of the Hill equation to the peak current data, yielding an $\mathrm{ED}_{50}$ value of $728 \mathrm{~nm}$ and a Hill coefficient of 2.2. A minimum of four neurons were examined at each capsaicin concentration for desensitization responses, whereas the numbers of neurons contributing to the peak current data are indicated next to the data points. observed in SIS and BAPTA-IS ( $p=0.31$ ); (2) for $1 \mathrm{~mm}$ external $\mathrm{Ca}^{2+}$, BAPTA-IS had significantly less tachyphylaxis than SIS $(p=0.03)$, and BAPTA-IS and EGTA-IS (data not shown) did not differ significantly ( $p=0.61)$; and (3) for $5 \mathrm{~mm}$ external $\mathrm{Ca}^{2+}$, there was no significant difference in tachyphylaxis among the three internal solutions $(p>0.64)$. All of the above $p$ values are unadjusted values resulting from a post hoc analysis of individual group means.

\section{Desensitization and capsaicin concentration}

We examined the acute desensitization and tachyphylaxis behavior as a function of capsaicin concentration $(0.05-5 \mu \mathrm{M})$ in the SES and SIS solutions, as summarized in Figure 6. The degree of acute desensitization to single applications of capsaicin ranging from $50 \mathrm{~nm}$ to $5 \mu \mathrm{M}$ was assessed as the fraction of peak current, which declined to a steady state level during the application (Fig. 6 , open circles). The degree of tachyphylaxis was assessed as the fraction of peak current response to a brief initial capsaicin application that was absent during a second application $20 \mathrm{sec}$ later (Fig. 6, open triangles). Statistical analysis of the data reveal that the degree of acute desensitization was not dependent on capsaicin concentration ( $p=0.32$, one-way ANOVA). Likewise, although a substantial decrease in the current amplitude occurred between the first and second capsaicin applications, there was little difference evident in the extent of current reduction among the capsaicin concentrations examined ( $p=0.18$, one-way ANOVA). Both types of desensitization were also tested across this capsaicin concentration range for the $0 \mathrm{Ca}$ SES/BAPTA-IS condition (results not shown). Although there was a pronounced reduction in the overall degree of acute desensitization and tachyphylaxis recorded in the absence of extracellular calcium, there was no significant effect of capsaicin concentration on the desensitization behavior.

The absence of agonist concentration dependence for desensitization stands in sharp contrast to the concentration dependence of inward current activation. For comparison, the dose-response relationship for capsaicin-induced currents is shown in Figure 6 (filled circles), which reveals a steep dependence of current activation on agonist concentration. The Hill coefficient of 2.2 suggests possible cooperativity between two capsaicin molecules to activate a conductance increase. Consequently, it seems that the activation of additional receptors by higher concentrations of capsaicin and the corresponding larger inward currents fail to produce a significantly greater degree of acute desensitization or tachyphylaxis.

\section{Barium and desensitization}

The ability of barium to substitute for calcium in various biological processes is often thought to reveal fundamental insights into the mechanisms of divalent cation regulation. We thus examined the desensitization of capsaicin-activated currents (acute and tachyphylaxis) with an external solution containing $2 \mathrm{mM} \mathrm{Ba}^{2+}$ in place of calcium (Ba-ES) and three different internal solutions (SIS, EGTA-IS, and BAPTA-IS). In general, the capsaicin responses recorded in Ba-ES were smaller in amplitude than the currents observed in SES, supporting the notion that calcium permeates the capsaicin-gated channels more readily than does barium. Specifically, the mean current amplitude of $0.61 \pm 0.13$ $\mathrm{nA}(n=36)$ measured in Ba-ES was significantly less than the mean values for both the SES condition $(2.17 \pm 0.33 \mathrm{nA} ; n=30)$ and the $0 \mathrm{Ca}$ SES condition $(3.55 \pm 0.30 \mathrm{nA} ; n=22 ; p<0.0001$, one-way ANOVA).

For all three internal conditions (SIS, EGTA-IS, and BAPTAIS), the capsaicin-activated currents exhibited substantial declines during agonist application in Ba-ES, demonstrating that this divalent can effectively support acute desensitization (Fig. 7A, open bar). Although there was no statistical difference in the level of acute desensitization observed in Ba-ES among the three internal solutions ( $p=0.25$, one-way ANOVA), the mean level of desen- 


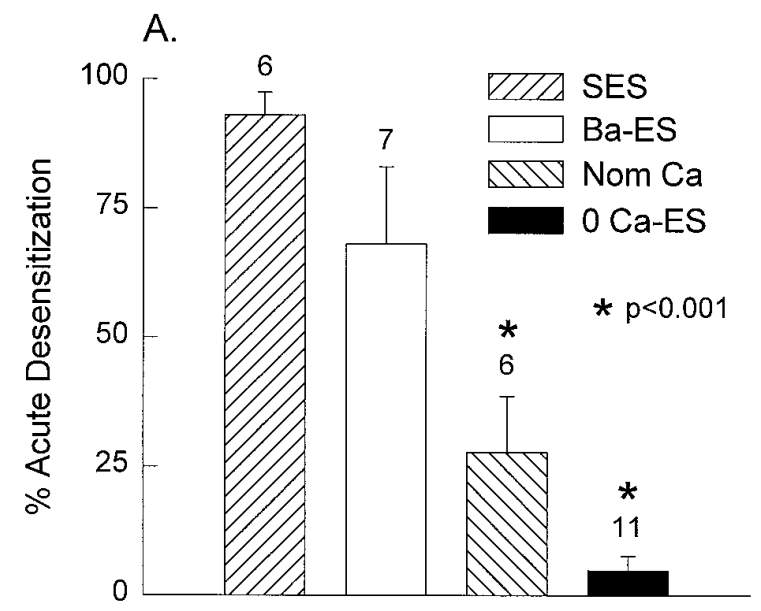

B.

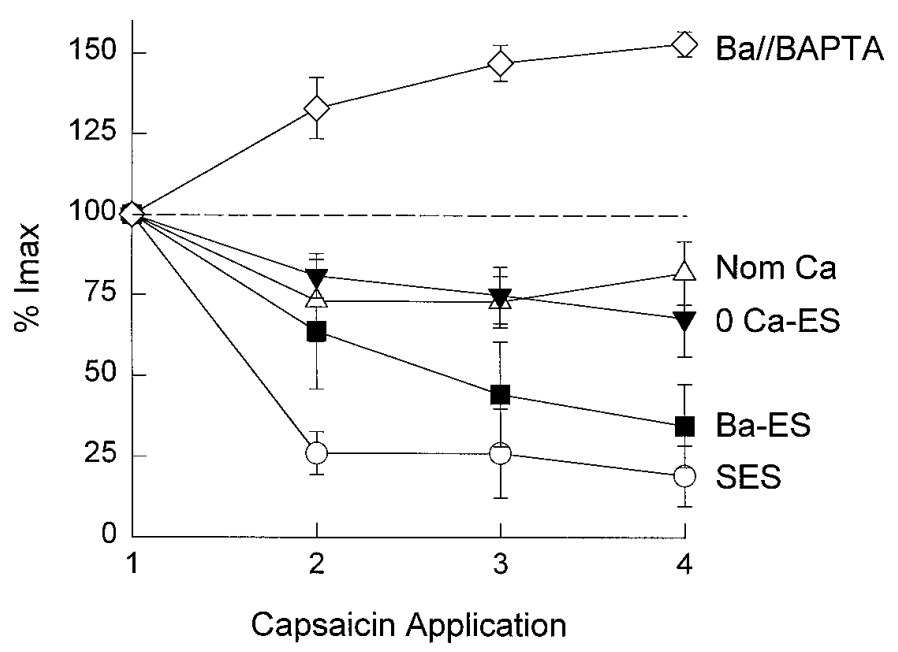

Figure 7. Barium can partially substitute for calcium in support of desensitization. $A$, Acute desensitization is measured as the percentage of peak current that decays during a single $60 \mathrm{sec}$ application of $1 \mu \mathrm{M}$ capsaicin (mean $\pm \mathrm{SEM}$ ) for the indicated extracellular solutions. The desensitization in nominal calcium or $0 \mathrm{Ca}-\mathrm{ES}$ is significantly less than that in either calcium- or barium-containing externals $(p<0.001$; MANOVA with Tukey-Kramer correction). $B$, Tachyphylaxis is represented by the decline in maximum current with successive $60 \mathrm{sec}$ applications of capsaicin $(1 \mu \mathrm{M})$ in the indicated external solutions (open triangles, nominal $\mathrm{Ca}^{2+}, n=6$; inverted filled triangles, $0 \mathrm{Ca}-\mathrm{ES}, n=10$; filled squares, Ba-ES, $n=5$; open circles, SES, $n=4$ ). Data points are mean (bars, $\pm \mathrm{SEM}$ ) fractional current. A 2 min interval separated each consecutive application. Again it can be seen that barium and calcium support comparable desensitization. Potentiation of current is seen in cells exposed to Ba-ES and internal BAPTA-IS (open diamonds, $n=5$ ).

sitization was less during dialysis with BAPTA-IS (data not shown).

The capsaicin-activated currents recorded in external barium also exhibited tachyphylaxis. It can be seen in Figure $7 B$ ( filled squares) that substantial tachyphylaxis occurs with consecutive applications of capsaicin in the Ba-ES and SIS solutions. As mentioned previously, an anomalous current potentiation occurred occasionally in the presence of external barium during the tachyphylaxis experiments. This increase in amplitude was observed with all three internal chelation conditions; however, with
BAPTA-IS, the potentiation of the capsaicin-activated current was the exclusive response, because none of the cells showed tachyphylaxis (Fig. $7 B$, open diamonds; $n=5$ ). This is in contrast to the acute desensitization observed with barium under the same conditions.

\section{Comparison of desensitization in calcium, barium, nominal calcium, and calcium-free solutions}

The observation that acute desensitization and tachyphylaxis are supported in the barium-containing solution raised the question of whether residual calcium rather than barium actually mediates this desensitization. Because no external EGTA chelation was present in the Ba-ES solution, contaminating calcium from the water and stock solutions could potentially reach micromolar concentrations. To address this issue, we assessed acute desensitization and tachyphylaxis in an nominal $\mathrm{Ca}$ external solution (Nom-Ca-ES).

The desensitization behavior for the four external solutions (SES, Ba-ES, nom-Ca-ES, and 0 Ca-ES) and the SIS internal solution are compared in Figure 7. Figure $7 A$ indicates that the degree of acute desensitization was highest in SES, reduced in $\mathrm{Ba}-\mathrm{ES}$, and lowest in the nominal and $0 \mathrm{Ca}$ solutions. There was significantly greater acute desensitization in SES and Ba-ES when compared with the two external solutions containing no added divalent cation $[p<0.001$, multivariate ANOVA (MANOVA), Tukey-Kramer]. Moreover, there was no significant difference in the acute desensitization observed for the SES and Ba-ES solutions ( $p>0.05$, MANOVA, Tukey-Kramer).

Figure $7 B$ shows that the degree of tachyphylaxis was most pronounced in external calcium, reduced in barium, and smallest in the nominal and $0 \mathrm{Ca}$ external solutions, consistent with the observations on acute desensitization. A statistical analysis of the tachyphylaxis observed for the second capsaicin application indicated that there was no significant difference among the four solutions ( $p=0.059$, one-way ANOVA), suggesting that a calcium-independent process may also contribute to the reduction in current amplitude. Nonetheless, comparison of the third and fourth applications clearly indicates that external barium does support greater tachyphylaxis than observed in the nominal and 0 Ca conditions.

\section{Desensitization and nucleotide analogs}

Intracellular calcium can modulate the process of desensitization through a variety of mechanisms. Ligand- and voltage-gated ion channels that conduct inward calcium currents can be desensitized or inactivated by mechanisms involving kinases and phosphatases, calcium, and voltage (Inoue et al., 1986; Kalman et al., 1988; Chen et al., 1990; Clark et al., 1990). For example, the inactivation of high voltage activated calcium channels and $\mathrm{GABA}_{\mathrm{A}}$ receptors can be regulated by a $\mathrm{Ca}$ - and calmodulin-dependent dephosphorylation event (Chad and Eckert, 1986; Armstrong and Eckert, 1987; Chen et al., 1990).

In the case of capsaicin responses, the only intracellular manipulation thus far reported to affect tachyphylaxis is an inhibition of the specific calcium- and calmodulin-dependent phosphatase calcineurin (Yeats et al., 1992; Docherty et al., 1996). Based on this suggestion that phosphorylation reactions are possibly involved in desensitization, we examined the influence of changing intracellular nucleotides on the acute desensitization and tachyphylaxis to capsaicin. To examine the potential contribution of GTP-binding proteins to desensitization, we compared capsaicin-activated currents recorded in internal solutions containing no added GTP, 100 

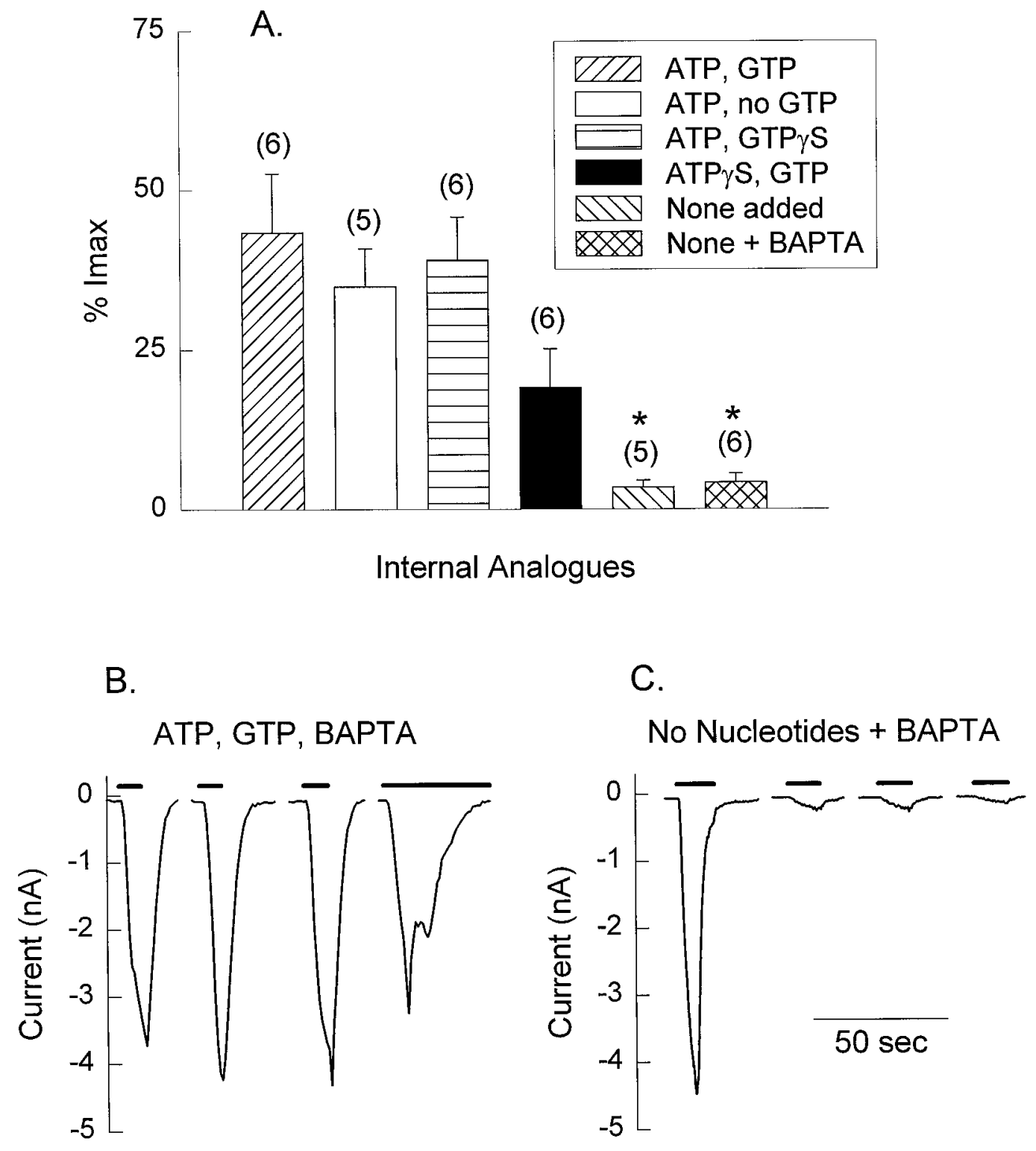

Figure 8. Tachyphylaxis of capsaicin responses is dependent on intracellular nucleotides. $A$, Current evoked during the second of four consecutive capsaicin applications $(1 \mu \mathrm{M})$ expressed as a percentage of the maximum current obtained during the first application (mean $\pm \mathrm{SEM}$ ) in various combinations of intracellular adenosine or guanosine nucleotides (see inset). Removal of all intracellular nucleotides resulted in dramatically stronger tachyphylaxis $(p<$ 0.01 ; MANOVA with Tukey-Kramer correction). Chelation of intracellular calcium by BAPTA does not mimic $(B)$ or prevent $(C)$ the potentiation of tachyphylaxis by removal of internal nucleotides during consecutive capsaicin applications. Each set of traces is from a separate neuron, and gaps in the traces represent 2 min interdose intervals.

$\mu \mathrm{M}$ GTP, or $500 \mu \mathrm{M}$ GTP $\gamma \mathrm{S}$. The nucleotide ATP is necessary for intracellular phosphorylation events, as well as energy-dependent pumps and transport systems. To assess the role of ATPdependent mechanisms, capsaicin responses were recorded in internal solutions that contained $2 \mathrm{~mm} \mathrm{MgATP,} 2 \mathrm{~mm} \mathrm{ATP} \gamma \mathrm{S}$, or no added ATP. In all of these experiments, SES was the external solution, and the internal solution was identical to SIS except for the absence or presence of the respective ATP and GTP analogs. The nucleotide regenerating system was included in all internal solutions except for the conditions with no added ATP or GTP.

Tachyphylaxis was assessed using successive exposures to $1 \mu \mathrm{M}$ capsaicin as described previously. A summary of the tachyphylaxis results for the various internal solutions is shown in Figure $8 A$ as the percentage of reduction in the $I_{\max }$ for the second capsaicin challenge. There was no significant difference in the level of current reduction for the internal solutions containing combinations of ATP and GTP analogs ( $p>0.05$, MANOVA, Tukey-Kramer). In contrast, a dramatically larger tachyphylaxis was observed for the internal solution with no added nucleotides $(p<0.01)$.

This result implicates a role for ATP and/or GTP in the tachyphylaxis processes regulating the desensitization state of the capsaicin-activated channels. An alternative explanation for these data is that the significant enhancement of tachyphylaxis results from the absence of intracellular calcium chelation by ATP itself. The exclusion of ATP from an internal solution containing no other Ca chelator might be expected to result in higher concentrations of intracellular calcium after a capsaicin response, consequently mediating a larger tachyphylaxis compared with ATPcontaining internal solutions. To test this possibility, calcium chelation was restored to the internal solution containing no added nucleotides by the addition of $10 \mathrm{~mm}$ BAPTA. If calcium chelation by ATP is replaced by BAPTA, one would expect to reverse the enhanced degree of tachyphylaxis seen in the absence of nucleotides. In contrast to this expectation, the mean level of current reduction for the second capsaicin application was similar for internal solutions containing no added nucleotides regardless of the absence or the presence of BAPTA (Fig. $8 A$ ). The enhanced tachyphylaxis observed in the absence of nucleotides is illustrated by comparing the current traces recorded in one neuron dialyzed with BAPTA-IS containing ATP and GTP (Fig. 8B) with those obtained in another neuron dialyzed with BAPTA-IS and no added nucleotides (Fig. 8C). Overall, these results suggest that ATP is not simply acting as a calcium chelator but may 
A.

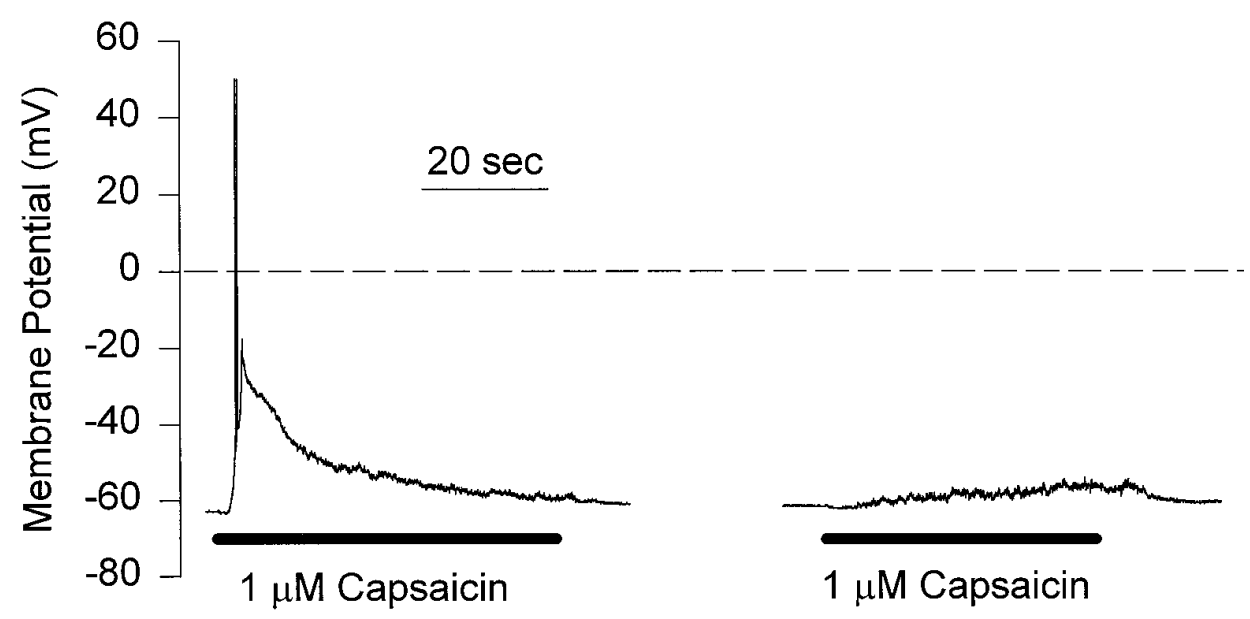

Figure 9. Desensitization of membrane potential responses to continuous and consecutive applications of capsaicin under current-clamp conditions. $A$, One micromolar capsaicin (horizontal bars) evokes a strong depolarization, triggering a pair of action potentials in a DRG neuron. The depolarization subsides in the continuous application of capsaicin. A subsequent reapplication of capsaicin after a 2 min interval elicits only a weak depolarizing response. $B$, In another neuron a lower concentration of capsaicin (30 nM) elicits a strong depolarization and a burst of action potentials. The depolarization is blunted but maintained during the application of agonist. A subsequent reapplication of capsaicin $(1 \mu \mathrm{M})$ elicits a second, transient response.

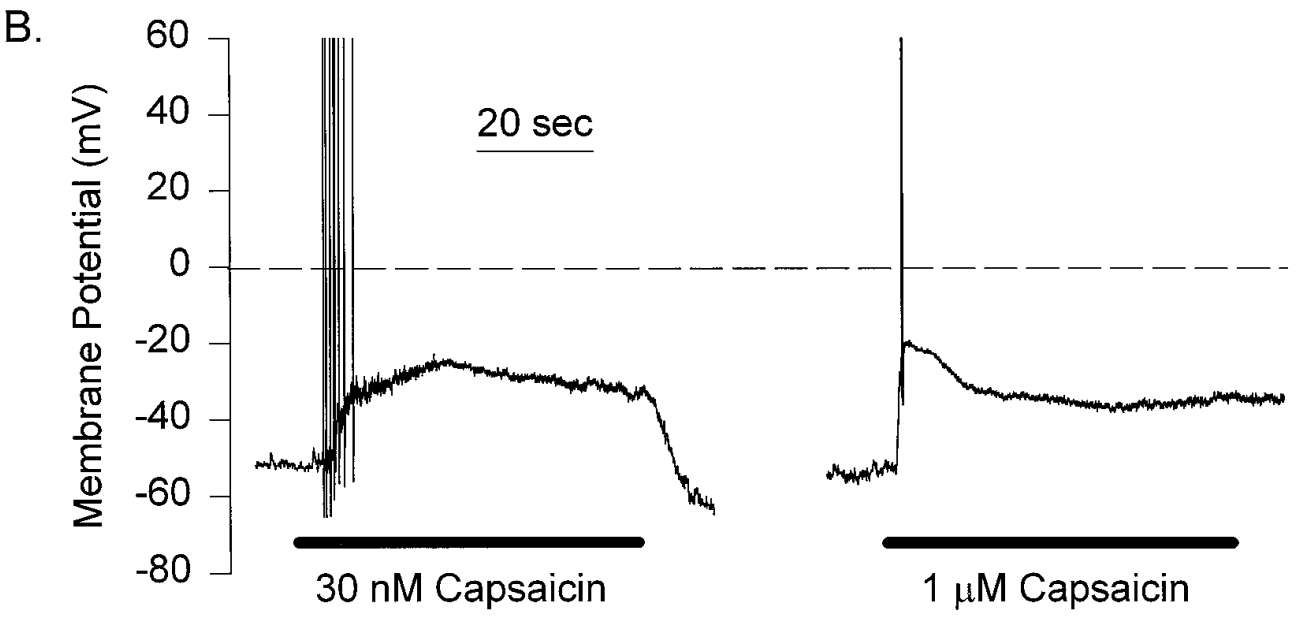

support a phosphorylation event that normally limits the degree of tachyphylaxis.

In contrast to the effects on tachyphylaxis, the various manipulations of ATP and GTP nucleotides had no effect on the acute desensitization of the capsaicin-activated currents (results not shown). A dramatic acute desensitization (90\%) occurred in all internal solutions tested, but the absence or presence of the various analogs had no significant effect ( $p=0.70$, one-way ANOVA). These results suggest that the processes responsible for acute desensitization of capsaicin-activated channels are independent of ATP-dependent phosphorylation and GTP-binding proteins.

\section{Desensitization in current clamp}

The primary effect of capsaicin on sensitive DRG neurons is excitation reflected by depolarization and the generation of action potentials. Although a decline in capsaicin-activated cation currents during exposure to agonist under voltage-clamp conditions provides a clear indication of desensitization, the consequence of this phenomenon to the responsiveness of normal neurons is not clear. To determine whether the desensitization observed under voltage-clamp conditions influenced neuronal excitability under more physiological conditions, we examined voltage responses to continuous or repeated applications of capsaicin under currentclamp conditions.

A typical membrane potential response to $1 \mu \mathrm{M}$ capsaicin recorded in SES and SIS solutions is shown in Figure $9 A$. After an initial delay, the neuron depolarized and fired a single action potential. The response exhibited acute desensitization as the membrane potential returned almost completely to the resting potential. Acute desensitization of the capsaicin response was observed in all seven cells tested with $1 \mu \mathrm{M}$ capsaicin. Tachyphylaxis was also present, because only a minimal depolarization was produced by the second capsaicin application (Fig. 9A).

Capsaicin was also tested at a concentration of $30 \mathrm{~nm}$. As seen in Figure $9 B$, there was a minimal acute desensitization of the capsaicin-induced depolarization. Although the failure of this neuron to continuously fire action potentials after the initial train of spikes suggests that some acute desensitization may have occurred, an alternative explanation is that the voltage-gated $\mathrm{Na}$ channels responsible for the spikes became inactivated. Acute desensitization occurred in only two of five cells challenged with $30 \mathrm{~nm}$ capsaicin, suggesting that lower capsaicin concentrations produce less acute desensitization under current-clamp conditions. In contrast, tachyphylaxis was observed in all five cells tested with $30 \mathrm{~nm}$ capsaicin. An example of a capsaicin application series is shown in Figure $10 \mathrm{~A}$. The first capsaicin challenge produced an initial train of action potentials and an extended depolarization. During the subsequent capsaicin deliveries, no action potentials were observed, and the depolarization of the membrane potential was reduced.

Because the whole-cell configuration necessitates a disruption of the plasma membrane, possibly disrupting calcium-buffering 


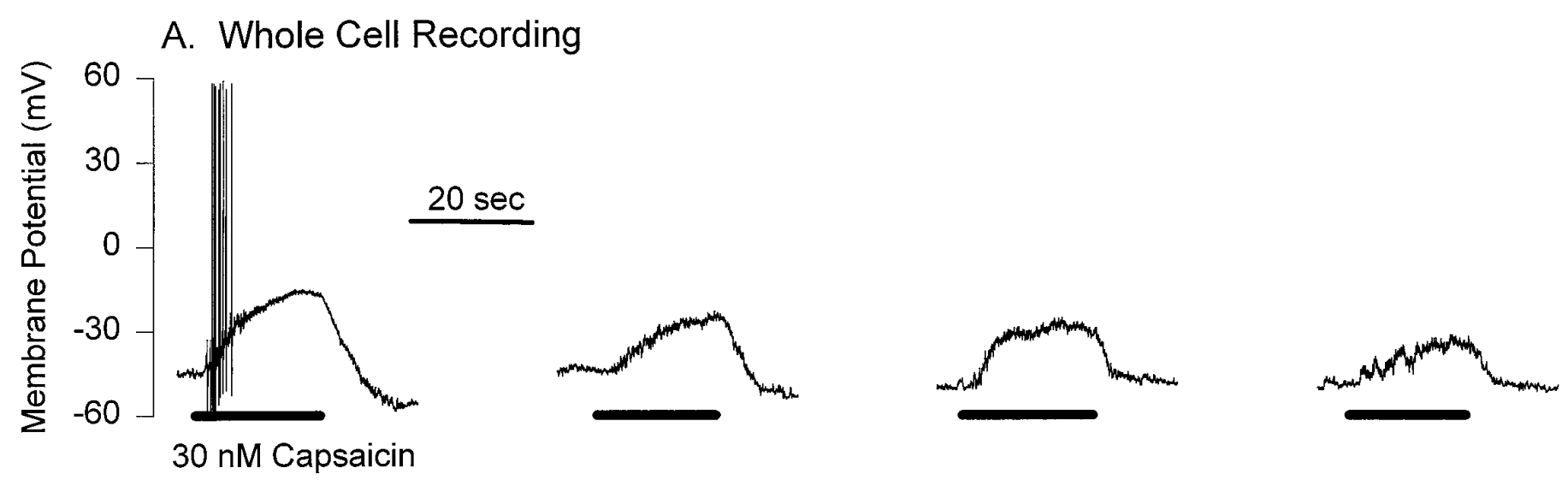

B. Perforated Patch Recording
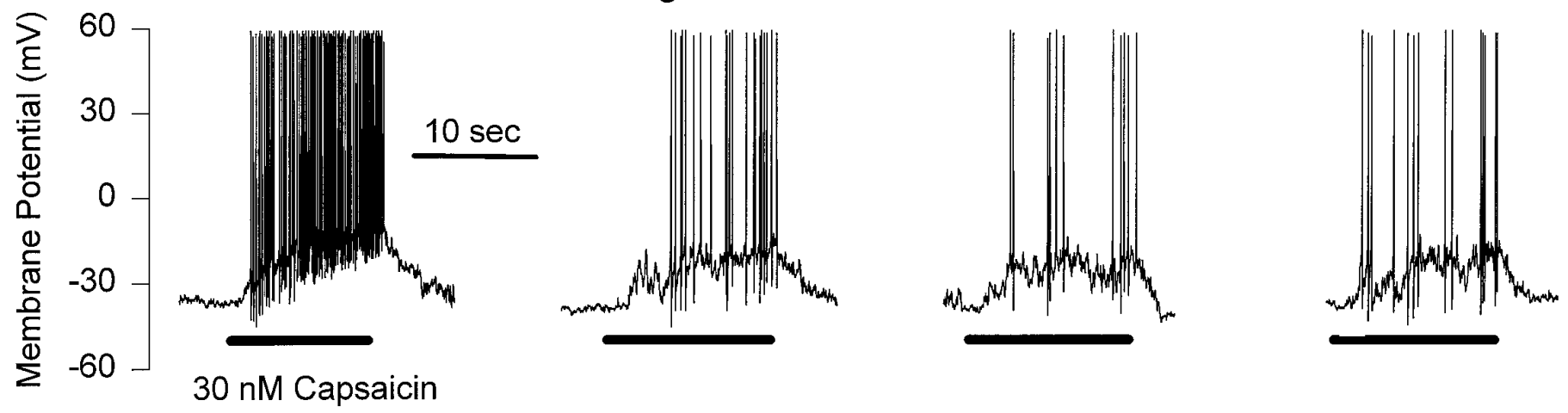

Figure 10. Tachyphylaxis of capsaicin voltage responses. $A$, Whole-cell membrane potential recordings in a DRG neuron during consecutive applications (horizontal bars) of $30 \mathrm{~nm}$ capsaicin separated by intervals of $2 \mathrm{~min}$. Note the progressively weaker response with each additional agonist application. $B$, Another neuron recorded under perforated patch conditions and exposed to consecutive capsaicin applications. Despite the intact intracellular milieu afforded by this recording method, subsequent capsaicin responses were again weaker with successive applications.

capacity and signaling components critical for cellular responses, we also investigated the desensitization of capsaicin responses with the perforated patch technique. In general there was no difference in the desensitization of responses to $30 \mathrm{~nm}$ capsaicin recorded with the perforated patch technique versus the wholecell recording mode. Acute desensitization was observed for three of eight cells, and tachyphylaxis occurred in five of six cells tested (e.g., Fig. 10B). These data suggest that the desensitization of capsaicin responses is not substantially different in intact versus dialyzed neurons. This conclusion is supported by results from voltage-clamp experiments completed with amphotericin B (results not shown) in which there was no significant difference in desensitization of capsaicin-activated currents in neurons recorded with perforated patch and whole-cell techniques.

\section{DISCUSSION}

The precise mechanisms underlying desensitization of capsaicin responses are not known. Our results, however, provide additional clues linking the phenomena to calcium-dependent processes. In summary, our data demonstrate that both acute desensitization and tachyphylaxis of the capsaicin-activated current are dependent on calcium concentration and independent of capsaicin concentration. There was no correlation between the overall extent of acute desensitization and tachyphylaxis within a given cell, suggesting that these two desensitization processes operate independently to modulate capsaicin receptors. Our divalent cation substitution experiments indicate that barium can successfully support both acute desensitization and tachyphylaxis, although less effectively than does calcium. However, during intracellular divalent chelation barium still supports acute desensitization while inducing a potentiation of current during consecutive capsaicin applications. This again suggests separable processes for the two forms of desensitization. The reduced ability of barium to stimulate the desensitization machinery within the cell may reflect a lower affinity or slower activation of divalent-dependent mechanisms by barium. Both types of desensitization were also observed for a subset of capsaicin responses in the absence of external calcium or barium, indicating that calcium-independent processes can mediate some acute desensitization and tachyphylaxis (see Figs. $3 C$ and $5 C$ ).

\section{Acute desensitization}

The dependence of acute desensitization on both the external calcium concentration and the presence and identity of an internal chelating agent suggests that a critical calcium concentration must be established on the intracellular membrane surface for activation of the acute desensitization process. At the lower external calcium concentration of $1 \mathrm{~mm}$, the acute desensitization was not only sensitive to the presence of an intracellular chelator but was differentially affected by EGTA and BAPTA, which exhibit varying speeds of calcium chelation. Above a $2 \mathrm{~mm}$ external $\mathrm{Ca}^{2+}$ concentration the acute desensitization process was insensitive to the presence of internal chelators at relatively high concentrations. 
A major question regarding the mechanism of acute desensitization is whether the calcium critical for activation of the process enters the cell through capsaicin-dependent channels or is released from internal calcium stores by calcium-induced calcium release or other mechanisms such as inositol triphosphatedependent release. Calcium-imaging experiments (Oxford et al., 1995) revealed a capsaicin-dependent increase in intracellular calcium concentration that was maintained throughout a $1 \mathrm{~min}$ capsaicin application. Thus an elevation of internal calcium is maintained for the same interval in which the capsaicin-activated current exhibits acute desensitization. From the results of the caffeine experiments, an increase in calcium concentration at the intracellular surface of the channel is sufficient to enhance acute desensitization in the absence of external calcium and calcium influx. Although a nonspecific block of the capsaicin-activated current by caffeine would produce a similar result, a pharmacological block of ion current has not been reported as a mechanism for caffeine action (Nehlig et al., 1992; Sawynok and Yaksh, 1993).

The limited observations of single capsaicin-gated channels also suggest that acute desensitization requires the presence of some intracellular factor. In the report of Forbes and Bevan (1988), there is no mention of any desensitization of single channel activity in cell-free membrane patches. Similarly, little acute desensitization is evident in the single channel records of Dray et al. (1990). Such continuous single channel activity in the excised patches exposed to capsaicin and calcium suggests that the calcium-dependent mechanism necessary for the acute desensitization of capsaicin-gated channels is not expressed within the isolated membrane patch and may require some cytoplasmic component.

Our observations that acute desensitization depends on the internal calcium concentration represent the first mechanistic evidence on the process of acute capsaicin desensitization. Our internal nucleotide experiments indicate that acute desensitization most likely does not involve ATP- or GTP-dependent mechanisms. This conclusion assumes that the endogenous nucleotides were sufficiently replaced or eliminated within the 5 min cytoplasmic dialysis before agonist application. In addition, the possible role of various intracellular signaling components should be tested, including phosphatases, phospholipases, and cytoskeletal components. In this regard, it has been recently proposed that ATP and calcium modulate the activity of NMDA channels by affecting the state of actin polymerization in the cytoskeleton (Rosenmund and Westbrook, 1993). A series of detailed single channel experiments would allow the investigation of the cellular machinery necessary and sufficient to support acute desensitization of capsaicin-activated channels.

\section{Tachyphylaxis}

Similar to acute desensitization, tachyphylaxis of capsaicinactivated currents is sensitive to the concentration of free internal calcium. The apparent dose-response curve for the external calcium dependence of capsaicin tachyphylaxis is shifted toward higher calcium levels by adding intracellular divalent chelators EGTA and BAPTA (see Fig. 5). The differential success of EGTA and BAPTA chelation at blocking tachyphylaxis in $2 \mathrm{~mm}$ external $\mathrm{Ca}^{2+}$ (see Fig. 5B,C) suggests that the internal calcium necessary for tachyphylaxis must reach a critical concentration within a particular interval to trigger tachyphylaxis successfully. However, we cannot yet establish the critical calcium concentration required to trigger tachyphylaxis, because we lack experimental data with various fixed concentrations of intracellular calcium.
The intracellular mechanism responsible for tachyphylaxis of the capsaicin-dependent current is activated during the initial capsaicin response. The interval between the first and second capsaicin applications can be varied over a wide range from $30 \mathrm{sec}$ to $20 \mathrm{~min}$ with no change in the level of tachyphylaxis observed for the second capsaicin response (results not shown). This extreme time window for the tachyphylaxis process suggests at least two possibilities for the type of cellular mechanism involved: (1) a specific enzymatic modification of the capsaicin receptor or associated protein responsible for inactivation of the channels is relatively "irreversible" for at least $20 \mathrm{~min}$; or (2) the tachyphylaxis of capsaicin-activated channels is mediated by a process activated during the first capsaicin response and continuously operating for an extended period. One possible event that could continuously activate the tachyphylaxis process would be a prolonged elevation of internal calcium levels after a capsaicin challenge. In the calcium-imaging experiments of Cholewinski et al. (1993), intracellular calcium responses to $0.1 \mu \mathrm{M}$ capsaicin remained elevated after the removal of capsaicin and exhibited a tachyphylaxis that required $40 \mathrm{~min}$ for a full recovery. Using imaging of fluo-3 responses we have confirmed this observation, indicating that calcium elevations triggered by capsaicin can outlive agonist application by a considerable period. Thus calciumdependent enzymatic processes may be prolonged because of the time course of calcium elevation.

A limited amount of information regarding the cellular mechanisms involved in tachyphylaxis can be derived from the nucleotide experiments in which the reduction of current was significantly enhanced in the absence of ATP and GTP in the internal solution. The important nucleotide seems to be ATP, because the exclusion of GTP alone had no effect on tachyphylaxis. It is possible, however, that internal ATP may have been converted to GTP by transphosphorylating enzymes, thereby maintaining a GTP supply within the cytoplasm. The increased tachyphylaxis observed in the absence of added ATP is not because of a simple removal of ATP-dependent calcium chelation, because the addition of BAPTA failed to reverse the effect. This result suggests that an ongoing ATP-dependent event actually limits the extent of tachyphylaxis experienced by the capsaicin-activated channels. Possibly, a kinase-mediated phosphorylation of the capsaicin receptor-channel complex or associated protein interferes with modulation by the tachyphylaxis machinery; alternatively, a simple dephosphorylation of a critical protein may be responsible for tachyphylaxis. In support of a phosphorylation role, Yeats et al. (1992) observed an increase in the extent of tachyphylaxis in the presence of nonspecific kinase inhibitors. Furthermore, the inhibition of the calcium- and calmodulin-dependent phosphatase calcineurin has been the only intracellular manipulation reported to block tachyphylaxis successfully (Yeats et al., 1992; Docherty et al., 1996). Moreover, evidence has been presented that barium (which supports desensitization) can activate calcineurindependent dephosphorylation independently of calcium and calmodulin (Verhage et al., 1995), consistent with our observations that barium can support desensitization in the absence of calcium.

\section{Summary}

The results presented in this paper contribute to understanding how calcium feeds back to desensitize capsaicin-activated channels. The importance of calcium in the desensitization of capsaicin responses is not surprising considering the role of calcium in the desensitization of other receptors, including the NMDA class of the glutamate receptor family (Clark et al., 1990; Legendre et al., 
1993) and the nicotinic acetylcholine receptor (Scubon-Mulieri and Parsons, 1977). The characterization of desensitization processes, such as those regulating the capsaicin response in rat DRG neurons, is crucial to understanding how sensory neurons can adapt their responses to repetitive stimuli in their environment. Furthermore, the future development and characterization of capsaicin analogs designed to combine increased desensitizing properties with decreased pungency may lead to a more effective therapeutic intervention for chronic pain conditions.

\section{REFERENCES}

Armstrong D, Eckert R (1987) Voltage-activated calcium channels that must be phosphorylated to respond to membrane depolarization. Proc Natl Acad Sci USA 84:2518-2522.

Benham CD, Evans ML, McBain CJ (1992) $\mathrm{Ca}^{2+}$ efflux mechanisms after depolarization evoked calcium transients in cultured rat sensory neurones. J Physiol (Lond) 455:567-583.

Bernstein JE (1987) Capsaicin in the treatment of dermatologic disease. Cutis 39:352-353.

Bevan S, Forbes CA (1988) Membrane effects of capsaicin on rat dorsal root ganglion neurones in cell culture. J Physiol (Lond) 398:28P.

Bevan S, Szolcsanyi J (1990) Sensory neuron-specific actions of capsaicin: mechanisms and applications. Trends Pharmacol Sci 11:330-333.

Bevan S, Hothi S, Hughes G, James IF, Rang HP, Shah K, Walpole CSJ, Yeats JC (1992) Capsazepine a competitive antagonist of the sensory neurone excitant capsaicin. Br J Pharmacol 107:544-552.

Breneman DL, Cardone JS, Blumsack RF, Lather RM, Searle EA, Pollack VE (1992) Topical capsaicin for treatment of hemodialysis-related pruritus. J Am Acad Dermatol 26:91-94.

Campbell E, Bevan S, Dray A (1993) Clinical applications of capsaicin and its analogues. In: Capsaicin in the study of pain (Wood JN, ed), pp 255-269. San Diego: Academic

Chad JE, Eckert R (1986) An enzymatic mechanism for calcium current inactivation in dialyzed helix neurons. J Physiol (Lond) 378:31-51.

Chen QX, Stelzer A, Kay AR, Wong RKS (1990) GABA receptor function is regulated by phosphorylation in acutely dissociated guineapig hippocampal neurones. J Physiol (Lond) 420:207-221.

Choi DW (1988) Glutamate neurotoxicity and diseases of the nervous system. Neuron 1:623-634.

Cholewinski A, Burgess GM, Bevan S (1993) The role of calcium in capsaicin-induced desensitization in rat cultured dorsal root ganglion neurons. Neuroscience 55:1015-1023.

Clark GD, Clifford DB, Zorumski CF (1990) The effect of agonist concentration, membrane voltage and calcium on $N$-methyl-D-aspartate receptor desensitization. Neuroscience 39:787-797.

Docherty RJ, Yeats JC, Bevan S, Boddeke HW (1996) Inhibition of calcineurin inhibits the desensitization of capsaicin-evoked currents in cultured dorsal root ganglion neurones from adult rats. Pflügers Arch 431:828-837.

Dray A (1992) Neuropharmacological mechanisms of capsaicin and related substances. Biochem Pharmacol 44:611-615.

Dray A, Dickenson A (1993) Capsaicin, nociception, and pain. In: Capsaicin in the study of pain (Wood JN, ed), pp 239-253. San Diego: Academic

Dray A, Forbes CA, Burgess GM (1990) Ruthenium red blocks the capsaicin-induced increase in intracellular calcium and activation of membrane currents in sensory neurones as well as the activation of peripheral nociceptors in vitro. Neurosci Lett 110:52-59.

Epstein JB, Marcoe JH (1994) Topical application of capsaicin for treatment of oral neuropathic pain and trigeminal neuralgia. Oral Surg Oral Med Oral Pathol 77:135-140.

Forbes CA, Bevan S (1988) Properties of single capsaicin-activated channels. Soc Neurosci Abstr 14:642.

Forscher P, Oxford GS (1985) Modulation of calcium channels by nor- epinephrine in internally dialyzed avian sensor neurons. J Gen Physiol 85:743-763.

Holliday J, Adams RJ, Sejnowski TJ, Spitzer NC (1991) Calcium-induced release of calcium regulates differentiation of cultured spinal neurons. Neuron 7:787-796.

Holzer P (1988) Local effector functions of capsaicin-sensitive sensory nerve endings: involvement of tachykinins, calcitonin gene-related peptide and other neuropeptides. Neuroscience 24:739-768.

Horn VJ, Marty A (1988) Muscarinic activation of ionic currents measured by a new whole-cell recording method. J Gen Physiol 92:145-159.

Inoue M, Oomura Y, Yakushiji T, Akaike N (1986) Intracellular calcium ions decrease the affinity of the GABA receptor. Nature 324:156-158.

Jancso N, Jancso-Gabor A, Szolcsanyi J (1967) Direct evidence for neurogenic inflammation and its prevention by denervation and by pretreatment with capsaicin. Br J Pharmacol Chemother 31:138-151.

Kalman D, O'Lague PH, Erxleben C, Armstrong DL (1988) Calciumdependent inactivation of the dihydropyridine-sensitive calcium channels in $\mathrm{GH}_{3}$ cells. J Gen Physiol 92:531-548.

Katz B, Thesleff S (1957) A study of "desensitization" produced by acetylcholine at the motor end-plate. J Physiol (Lond) 138:63-80.

Legendre P, Rosenmund C, Westbrook GL (1993) Inactivation of NMDA channels in cultured hippocampal neurons by intracellular calcium. J Neurosci 13:674-684.

Liu L, Simon SA (1994) A rapid capsaicin-activated current in rat trigeminal ganglion neurons. Proc Natl Acad Sci USA 91:738-741.

Maggi CA (1991) Capsaicin and primary afferent neurons: from basic science to human therapy? J Auton Nerv Syst 33:1-14.

Marsh SJ, Stansfield CE, Brown DA, Davey R, McCarthy D (1987) The mechanism of action of capsaicin on sensory C-type neurons and their axons in vitro. Neuroscience 23:275-289.

Nehlig A, Daval J, Debry G (1992) Caffeine and the central nervous system: mechanisms of action, biochemical, metabolic and psychostimulant effects. Brain Res 17:139-170.

Oxford GS, Wagoner PK (1989) The inactivating $\mathrm{K}^{+}$current in $\mathrm{GH}_{3}$ pituitary cells and its modification by chemical reagents. J Physiol 410:587-612.

Oxford GS, Koplas PA, Rosenberg RL (1995) Characterization of capsaicin responses in intact rat dorsal root ganglion neurons. Soc Neurosci Abstr 21:1160.

Petersen M, LaMotte RH (1991) Relationships between capsaicin sensitivity of mammalian sensory neurons, cell size and type of voltage-gated Ca currents. Brain Res 561:20-26.

Rosenmund C, Westbrook GL (1993) Calcium-induced actin depolymerization reduces NMDA channel activity. Neuron 10:805-814.

Santicioli P, Patacchini R, Maggi CA, Meli A (1987) Exposure to calcium-free medium protects sensory fibers by capsaicin desensitization. Neurosci Lett 80:167-172.

Sawynok J, Yaksh TL (1993) Caffeine as an analgesic adjuvant: a review of pharmacology and mechanisms of action. Pharmacol Rev 45:43-75.

Schmigol A, Kirischuk S, Kostyuk P, Verkhratsky A. (1994) Different properties of caffeine-sensitive $\mathrm{Ca}^{2+}$ stores in peripheral and central mammalian neurones. Pflügers Arch 426:174-176.

Scubon-Mulieri B, Parsons RL (1977) Desensitization and recovery at the frog neuromuscular junction. J Gen Physiol 69:431-477.

Tsien RY (1980) New calcium indicators and buffers with high selectivity against magnesium and protons: design, synthesis, and properties of prototype structures. Biochemistry 19:2396-2404.

Verhage M, Hens JJ, DeGrann PN, Boomsma F, Wiegant VM, daSilva $\mathrm{FH}$, Gispen WH, Ghijsen WE (1995) $\mathrm{Ba}^{2+}$ replaces $\mathrm{Ca}^{2+} /$ calmodulin in the activation of protein phosphatases and in exocytosis of all major transmitters. Eur J Pharmacol 291:387-398.

Wallengren J (1991) Treatment of notalgia paresthetica with topical capsaicin. J Am Acad Dermatol 24:286-288.

Yeats JC, Boddeke HWGM, Docherty RJ (1992) Capsaicin desensitization in rat dorsal root ganglion neurones is because of activation of calcineurin. Br J Pharmacol 107:238P. 